\title{
The Impact of Teenagers' Digital Literacy on the Use of Social Media
}

\author{
Harisa Mardiana \\ \{harisa.mardiana@ubd.ac.id, soehanadiharisa@gmail.com\} \\ Department Informatics Engineering, Universitas Buddhi Dharma, Indonesia
}

\begin{abstract}
The biggest users of social media are teenagers. With a digital set, teenagers open up social media everywhere, so that, it is needed the strong and large controls from various parties. Besides that, in digital literacy knowledge, teenagers must understand the ability to use digital literacy because it will cause new problems by distributing content, sharing content or commenting on status. The purpose of this research is the involvement of teenagers in using social media and giving the problems when they share content, images, digital literacy, and desirable websites. Their involvement can cause big problems which can ultimately harm teenagers themselves, especially on digital literacy knowledge. This research aim is to investigate the involvement of teenagers on social media so that it can change all the order, language and content provided. The subject sample population numbered 273 teenagers aged 13-18 years. This research method is a mixed-method by using a questionnaire as a quantitative of research and observation and for qualitative using interviews conducted online or faces to face within 2-3 months to 22 teenagers. The result showed that teenagers are the subjects that use most social media, and also teenagers believe that social media helped them in solving the problem and also teenagers can change digital literacy and content to facilitate them in socializing.
\end{abstract}

Keywords: Social media, teenagers, digital knowledge, involvements.

\section{Introduction}

Teenagers who use social media show the landscape and technological development. Smartphone ownership has become a part of teenagers' lives everywhere. Teenagers grow and expect responses, satisfaction, and immediate notifications. Their minds evolve and adapt to changes in a moment so many of them lose direction [3]. The world is becoming more digital and digital literacy skills are becoming important [4]. Therefore, with the technological landscape, teenagers will quickly blend in because they are native technology, with the intention that they were born in the era of technology. The question is how teenagers can change social media by using their digital literacy knowledge [2]. The teenagers' involvement on social media means that they participate fully in making a decision which leads to having relationships with others on social media as rapidly and effortlessly as possible [15]. The problem is when a teenager posted the latest photo on social media in hopes of receiving praise from friends, but most of them bullied and mocked her or him with harsh words [8]. The other teenagers did not seem to care about someone else feeling. Compare to the previous research by Haddon, L (2015) that digital literacy is the knowledge and ability to use technology critically and creatively to find the information, solve the problems or complete 
tasks. And people who use digital literacy act safely and respectfully online. In his research, Haddon, L., (2005) that digital literacy is the knowledge and ability to use technology critically and creatively to find the information, solve the problems or complete tasks. On the other hand, in the use of digital literacy, teenagers can actually change social order, this research is not in line with Haddon L., (2005). This research that in line with previous authors (Anderson \& Jiang, 2018) which indicated that teenagers interpret digital literacy without an adequate process and are quickly carried away by emotional to reply to writing that they do not know the sources or it is a hoax. The impact of digital literacy not only affects human beings who are literate, but also on someone who is not literate. The lack of digital access to digital illiterate people will result in unskilled understanding and practice which results in a constantly changing digital landscape navigation [12]. This is in line with the problem in Indonesia, that teenagers are easily consumed by the issue and provoked without finding out the truth of the news or information [10]. The concern of digital literacy says that teenagers' problems in using social media such as hoaxes hate speech and cyberbullying have a negative impact along with the increase in technology and communication caused by not having digital literacy skills among teenagers [11]. The low level of digital literacy is closely related to the lack of public interest in reading. The involvement of teenagers on social media indicated that they feel more connected to important life contours. In sharing emotional connections and telling their feelings to others, teenagers feel cared for, even if the site can cause uncertainty or a problematic site [11]. And at the same time, teenagers point out that social media has a good impact and feel that social media has a relatively safe effect even in large schemes [12]. At it happens, the ability to use digital social media to mitigate risk before sharing other useful information can be a new problem. Many teenagers are easy to share and spread content without considering the effects that arise afterward. Also, teenagers do not pay attention to ethics when redistributing content [14]. Based on the previous researchers and problem in this research concluded that teenagers involve in social media included the changes in digital literacy knowledge and behavior. The purpose of the research is to investigate of the significant relationship between frequency-independent variable of teenagers in their involvement on social media.

\section{Method}

This study uses a quantitative method with a semi-structured qualitative method, which consists of testing theory by investigating the relationship between variables. The source of data collection is taken from questionnaires that had been spread out on Google Forms. The semi-structured qualitative method as the interview with the teenagers for 2-3 hours in the month of October-November, 2019. Data for the independent (predictor) variables were from questionnaires which the author used the 2 questions which dimension of information of teenagers, the involvement and social media.

\subsection{Hypothesis}

a) There is a statistically significant relationship between the frequency-independent variable of teenagers in their involvement in social media (H1)

b) There is a statistically significant relationship between frequency the independent variable social media which perceived the importance of teenagers and involvement on social media (H2) 
c) The independent variables frequency of teenagers as users and their involvement on social media $(\mathrm{H} 3)$

\subsection{Participants}

There are 273 participants for this research were teenagers at the age of 13 through 18 in which the questionnaires are from Google form in August - October 2019. Some of the teenagers live nearby and some of the teenagers are the students at the campus that the author has worked. All of the students are in school and none of those are out of school.

\subsection{Data Analysis}

Analysis of the data obtained from the answers to questionnaires provided. From data analysis, it is shown that the teenagers' reliability is 0.875 . It is strong and the reliability of social media is 0.738 . It showed strong reliability and the involvement is 0.897 , which is strong. For the correlation between teenagers and social media and their involvement is 0.761 , and social media and the involvement is 0.670 . The correlation among teenagers, social media and the involvement is 0.892 and it is shown that the correlations are strong. So, it is concluded that there is a significant relationship between teenagers and social media and their involvement. It means that the questionnaires are valid.

\section{Result and Discussion}

From the research questions, it can measure the relationship between frequencyindependent variables (teenagers) in the involvement of social media. To show the descriptive statistics frequency the independent variable of teenagers on their involvement on social media is shown in table 2 .

Table 1. Descriptive statistics of frequency teenagers' variable in their involvement and the frequency of

\begin{tabular}{|c|c|c|c|c|c|}
\hline \multicolumn{6}{|c|}{ Frequency of Teenagers' variables in their Involvements } \\
\hline Variables & Means & Median & SD & Freq. & $\begin{array}{l}\text { Percentage } \\
(\%)\end{array}$ \\
\hline Update status & 3.54 & 4.00 & 0.747 & 176 & 64.5 \\
\hline Place to talk & 3.62 & 4.00 & 0.729 & 197 & 72.2 \\
\hline Choose SM than real friends & 3.43 & 4.00 & 0.709 & 145 & 53.1 \\
\hline Before Sleep open SM & 3.51 & 4.00 & 0.676 & 160 & 58.6 \\
\hline Hobby & 3.63 & 4.00 & 0.634 & 191 & 70 \\
\hline \multicolumn{6}{|c|}{ Digital Literacy Knowledge Variable in their Involvement } \\
\hline $\begin{array}{l}\text { I never care about the people feel I do not } \\
\text { know }\end{array}$ & 3.59 & 4.00 & 0.642 & 170 & 65.6 \\
\hline Change digital literacy for information & 3.58 & 4.00 & 0.643 & 178 & 65.2 \\
\hline My friend only read the title & 3.57 & 4.00 & 0.578 & 164 & 60.1 \\
\hline SM never hurt me & 3.63 & 4.00 & 0.574 & 184 & 67.4 \\
\hline Open SM in all condition & 3.60 & 4.00 & 0.547 & 171 & 62.6 \\
\hline
\end{tabular}

From the data above of teenagers in using social media, it is shown that place to talk is coming of the first highest. It is 197 or $72.2 \%$ of teenagers that agreed on social media is the place to talk. According to Knorr, C, in Washington Post (2018); [5] and [20] stated that for 
teenagers the most comfortable place to talk is on social media. For digital literacy knowledge, teenagers answered the highest 184 or $76.4 \%$. They revealed that social media never hurt them and as the interview was done to some teenagers, social media is the place for them to talk, and they use their literacy that only teenagers can understand literacy.

The second highest from teenagers' frequency is a hobby 191 or $70 \%$. As the interview was taken, their hobby is having social media, they can interact, share, comments and give the information. This has become their habit that eventually their hobby based on social media. For changing on information digital literacy, the frequency is 178 or $65.2 \%$. It is shown that teenagers are capable on changing the information. In the interview, to change the digital literacy for information, they can do in real-time. According to Eshet-Alkalai \& Chajut, (2009) and Martin \& Grudziecki (2006) stated that as a concept digital literacy is a skill in technology to change information, share and exchange information. This ability uses productive communication also quickly navigation through the domains of knowledge, such as the internet and other media so that teenagers can change information quickly, in real-time.

The third highest from teenagers is update status (176 or $64.5 \%$ ). By updating their status, they feel that they are recognized by friends or others. Botou \& Marsellos (2018) revealed that the point of being recognized is that they have the same conventional ambitions for life, like a nice house, a good car, and expensive clothes. It shows self-esteem that is closely related to the ambition of personal qualities that creates and directs desirable and behavior. In digital literacy knowledge the third highest is open social media in all condition 171 or $62.6 \%$. In the interview, some of the teenagers mentioned that even when they are busy at school or work, they do not want to leave the social media, they open and look at the social media. Researcher Boyd, (2007) revealed that social media networking is a type of public networking with the ability to find friends, surf social media and viewers who do not appear to create their challenges from teenagers.

The fourth highest frequency of teenagers in their involvement is 160 or $58.6 \%$ who always open social media before going to bed at night, and in the interview, it is indicated that teenagers experience less sleep for reading or opening social media before going to bed at night after at 23.00 and wake up in a bad mood. According to Sellgren (2016), teenagers admitted that they cannot sleep before reading from social media and it can interfere with learning in school. For digital literacy knowledge (170 or $65.6 \%)$ which is the teenagers never care about the people feeling that they do not know. It means that the teenagers' empathy deficit. According to Madden, M. et, al (2013) empathy deficit is the teenagers have absence of empathy from the perspective of people side.

The fifth for the frequency of teenagers are choosing social media rather than in real life friends $(160$ or $58.6 \%)$. In the interview was done, some of the teenagers explained that almost all of the teenagers prefer texting and chatting online to hanging out with their friends in real life. In the interview for this matter, they like texting or chatting rather than hanging out with a friend, because they can talk to friends while doing something. Researchers Agosto et, all (2012); [23]; [22] indicated that teenagers feel less socially connected and even though they believe that they are part of their group of friends. In digital literacy knowledge with their involvement is talking about their friends only read the title (164 or $60.1 \%)$. As the interview was done, some teenagers were grumbling that their friends only read the title of the story they post on social media, and the rest, they may ask what it is. It does not surprise, many teenagers now send hoax or fake news or receive hoax news. The researcher Ba, Tally, and Tsikalas (2002) explained that digital literacy is a set of habits of teenagers in using information technology to learn, work and have fun. So these habits include the ability of individuals in 
problem-solving, the aim is to link skills in using technological tools, communication literacy, and web literacy.

From the results of the above, teenagers have an important role in social media and teenagers are the biggest users of social media. Social media sites are designed to share information and encourage everyone to do it. Teenagers' satisfaction is when there is sharing, reciprocal or feedback is posted and commented on, and it increased the use of social media and give satisfaction to teenagers. The relationship between teenagers and social media gives a good nuance to the life of teenagers. Feelings are valued and appreciated [26]. The relationship between social media linking and life satisfaction is a variety of substrates. And if parents understand and stop worrying about the conditions of teenagers, then surfing on social media is a good experience for teenagers [16]; [21]. Teenagers who do not have social media will find it difficult to connect with friends at school or wherever they are. Because social media is needed right now. In digital literacy knowledge, teenagers understand better than other parents or adults [28], in line with this research is from Rodriguez De Dios, et. al (2018) revealed that parents must contribute and have the opportunity to learn and technologically literate. Digital literacy skills for parents must be balanced and utilized technology appropriately. So that, parents and adult can help teenagers' problems on social media. Parents and adults responsibility must be tailored to the teenagers' needs such as when and how long teenagers spend time in front of a computers or devices.

\section{Conclusion}

Teenagers' involvement in social media is one aspect of technological change. People should give teenagers a chance that social media is not something to be afraid of. Instead, teenagers may contribute more on social media by giving good information, sharing information, giving comments properly. In digital literacy knowledge, teenagers should have handled the reading contents and time spending. Teenagers should crosscheck the absorbing information which provokes them without finding the truth of information. As teenagers involve in multi-literation through their participation from the website, they need to have utilized technology-mediated which showing the instruction and criticism of transformed in digital literacy knowledge. To locate information online, teenagers should have the ability and skills critically and accurately. Because teenagers are the users of technology in this era.

\section{References}

[1] K. DuBois , "How social media affects teens: Teens and Tech: Social Media Today," 19 May 2019. [Online]. Available: https:/www.justsayyes.org/topics/how-social-media-affects-teens/. [Accessed 20 February 2020].

[2] D. Reid and P. Weigle, "Social Media Use among Adolescents: Benefits and Risks," Adolescent Psychiatry, vol. 4, pp. 73-80, 2014.

[3] S. M. Al-Jubayer, "The Use of Social Networking Sites Among Teenagers: A Study of Facebook Use in Dhaka City," Journal of International Social Issues, vol. 2 , no. 1, pp. 35 - 44, March 2013.

[4] L. Haddon, "Social Media and Youth," The International Encyclopedia of Digital Communication and Society, First Edition, pp. 1-9, 2015.

[5] A. Adit, "Perhatikan 10 Hal Ini Agar Pembelajaran Daring Efektif," 17 March 2020. [Online]. Available: https://www.kompas.com/edu/read/2020/03/17/113921271/perhatikan-10-hal-ini-agar- 
pembelajaran-daring-efektif?page=all.

[6] P. Learning, "Wanted: digital literacy skills," Learning Potential Resources, 2017.

[7] G. Tambunsaribu, "The Use of Rude Words by Indonesian Teenagers: A Sociolinguistic Case," in Conference: Proceedings of the International Conference on Interdisciplinary Language, Literature and Education, 2018.

[8] D. Kurniawati, "The Impact Of Teenager Dependency To Social Media And The Anticipate Effort," INTERNATIONAL JOURNAL OF SCIENTIFIC \& TECHNOLOGY RESEARCH , vol. 7, no. 6, pp. 28-30, June 2018.

[9] V. Bell , D. Bishop and A. K. Przybylski , "The debate over digital technology and young people," BMJ, 2015.

[10] A. Lenhart, M. Anderson and A. Smith, "Chapter 4: Social Media and Romantic Relationships," 1 October 2015. [Online]. Available: https://www.pewresearch.org/internet/2015/10/01/socialmedia-and-romantic-relationships/.

[11] UNESCO, "International Literacy Day," UNESCO, Paris, 2017.

[12] B. Blummer, "Digital literacy practices among youth populations: A review of the literature," Education Libraries: Childrens Resources, vol. 31, no. 1, pp. 38-45, 2008.

[13] D. Miller and J. Sinanan, "Visualization Facebook," in How Social Media Change the World, London, London: UCL Press, 2016, pp. 155-180.

[14] J. Hur and M. Gupta, "Growing up in the Web of Social Networking: Adolescent Development and Social Media," Adolescent Psychiatry, vol. 3, no. 3, pp. 1-10, 2013.

[15] M. Anderson and J. Jiang, "Teens, Social Media \& Technology 2018," 31 May 2018. [Online]. Available: https://www.pewresearch.org/internet/2018/05/31/teens-social-media-technology-2018/. [Accessed 17 February 2020].

[16] G. Constantin, "Social Media Use May Mess With Teens' Sleep," 12 January 2020. [Online]. Available: https://thriveglobal.com/stories/social-media-use-may-mess-with-teens-sleep/.

[17] D. Agosto, J. Abbas and R. Naughton, "Relationships and social rules: Teens' social network and other ICT Selection Practices," Journal of the American Society for Information Science and Technology, vol. 63, no. 6, pp. 108-1124,, June 2012.

[18] R. Ehmke, "How Using Social Media Affects Teenagers," 2018. [Online]. Available: https://childmind.org/article/how-using-social-media-affects-teenagers/.

[19] M. Romero, "Digital literacy for parents of the 21st century children," Elearning Papers, vol. 38, pp. 32-40, 2014. 